\title{
Interfacial Reactions in Model NiTi Shape Memory Alloy Fiber-Reinforced Sn Matrix "Smart" Composites
}

\author{
J.P. COUGHLIN, J.J. WILLIAMS, G.A. CRAWFORD, and N. CHAWLA
}

In this article, the microstructure properties of a novel $\mathrm{Pb}$-free solder composite were examined. A binary nickel-titanium shape memory alloy (SMA) fiber was used to reinforce the Sn-rich matrix, to take advantage of the superelastic properties of the fiber. The objective of this study was to understand long-term, high-temperature interfacial growth in a model NiTi fiber-reinforced Sn matrix composite solder system. The microstructure was quantified by scanning electron microscopy (SEM), energy dispersive spectroscopy (EDS), and wavelength dispersive spectroscopy (WDS). The mechanical properties of the interfacial zone, e.g., Young's modulus and hardness, were characterized by nanoindentation. The evolution of the reaction products with time and the relationship between composition and local mechanical properties are discussed.

DOI: $10.1007 / \mathrm{s} 11661-008-9676-1$

(c) The Minerals, Metals \& Materials Society and ASM International 2008

\section{INTRODUCTION}

HEALTH concerns over $\mathrm{Pb}$ toxicity in traditional $\mathrm{Pb}-\mathrm{Sn}$ solders have prompted the need for $\mathrm{Pb}$-free solders in electronic packaging. ${ }^{[1-3]}$ In general, Sn-rich solder alloys based on binary and ternary eutectics of $\mathrm{Ag}$ and $\mathrm{Cu}$ exhibit significant advantages in creep and thermal fatigue resistance over Pb-Sn solders. ${ }^{[-6]}$ However, these replacement alloys exhibit inferior ductility to $\mathrm{Pb}-\mathrm{Sn}$ alloys. When these solder joints are subjected to mechanical stress during assembly, packaging, or in service, the poor ductility may result in failure of the component. ${ }^{[7,8]}$

The damage tolerance of these solder alloys may be improved by adding shape memory alloy (SMA) fibers to the Sn-rich solder matrix. Shape memory alloys exhibit excellent damage tolerance, up to strains as high as $10 \mathrm{pct}$ with no significant degree of permanent deformation. This is accomplished via two-phase-transformation mechanisms: (a) superelastic transformation and (b) thermally induced transformation. ${ }^{[10]}$ The superelastic transformation occurs when the SMA is strained above the austenite start temperature and transforms from austenite to martensite. After the sample is loaded above the critical transformation stress of the alloy, strain can be recovered simply by unloading and it reverts back to austenite. ${ }^{[9,10]}$ For the thermally induced transformation, plastic deformation can be

J.P. COUGHLIN, formerly Graduate Research Assistant, School of Materials, Fulton School of Engineering, Arizona State University, is Engineer with the Assembly Technology Division, Intel Corporation, Chandler, AZ 85224. J.J. WILLIAMS, Research Scientist, and G.A. CRAWFORD, Ph.D. Student, are with the School of Materials, Fulton School of Engineering, Arizona State University. N. CHAWLA, Professor, School of Materials and Department of Mechanical and Aerospace Engineering, is with Arizona State

University, Tempe, AZ 85287-8706. Contact e-mail: nchawla@asu.edu Manuscript submitted March 27, 2008.

Article published online October 25, 2008 recovered upon the application of heat, as the material returns to its original dimensions. A superelastic transformation may be desirable in a $\mathrm{Pb}$-free solder composite, because it does not require a heating cycle to recover deformation. Thus, if the SMA/solder composites are subjected to an external stress along the direction of the wire, a superelastic transformation will occur in the SMA fibers. When the external stress is removed, the SMA fibers should return to their original dimensions.

The NiTi SMAs are a good choice as reinforcement in composites due to their relatively low cost and unique properties. ${ }^{[1-19]}$ Binary $50-50$ at. pet NiTi alloys can have transformation temperatures just below $0{ }^{\circ} \mathrm{C}$ and a superelastic range between freezing and $250{ }^{\circ} \mathrm{C}$, making them excellent candidates for consumer electronics. When considering NiTi fiber-reinforced Sn matrix composites, the microstructure and properties of the interface between the solder and SMA fibers are very important. Bond strength between the matrix and reinforcement must be strong enough to provide load transfer, which is directly dependent on interfacial growth characteristics of the materials in the system. Therefore, it is necessary to have an in-depth understanding of interfacial reactions that take place during melting of the solder (liquid Sn) and NiTi.

The microstructure of NiTi fiber/solder composites has not been studied in detail. ${ }^{[19-23]}$ Dutta and co-workers ${ }^{[20]}$ fabricated $\mathrm{Sn}-3.8 \mathrm{Ag}-0.7 \mathrm{Cu}$ solder with a single 1-mm-diameter NiTi fiber and a fiber volume fraction of about $11 \mathrm{pct}$, cast at $533 \mathrm{~K}$. It was originally reported that an intermetallic of $\mathrm{Ni}_{3} \mathrm{Sn}_{4}$ was observed at the NiTi wire/solder interface for a $\mathrm{Sn}$-rich sample held at the reflow temperature of $533 \mathrm{~K}$ for approximately 3 minutes. This analysis was reversed in subsequent articles, ${ }^{[21,22]}$ where they identified a small reaction zone, via energy dispersive spectroscopy (EDS) line-scan analysis, consisting of interdiffused $\mathrm{Sn}$ and Ti. A clear understanding of the interaction between NiTi and $\mathrm{Sn}$ is 
required. The objective of this study is to understand long-term, high-temperature interfacial growth in a model NiTi fiber-reinforced Sn matrix composite solder system. The microstructure was quantified by scanning electron microscopy (SEM), EDS, and wavelength dispersive spectroscopy (WDS). The mechanical properties of the interfacial zone, e.g., Young's modulus and hardness, were characterized by nanoindentation.

\section{MATERIALS AND EXPERIMENTAL PROCEDURE}

Commercial NiTi wire (Memry Corporation, Bethel, CT), approximately $600 \mu \mathrm{m}$ in diameter, was used in this study. The wire was cold drawn, guide wire straightened, and annealed at $850{ }^{\circ} \mathrm{C}$ for 30 minutes followed by a water quench by the manufacturer. Differential scanning calorimetry was performed on the NiTi fiber to determine transformation temperatures. A schematic of the fabrication process for making the model single fiber composites is shown in Figure 1. The fiber was etched in an aqueous solution containing 4.8 pct $\mathrm{HF}$ and 10.5 pet $\mathrm{HNO}_{3}$ for 5 minutes to remove surface oxides. Pure $\mathrm{Sn}$ was melted in a tapered porcelain crucible at $300{ }^{\circ} \mathrm{C}$. The wire was dipped in a phosphoric acid-based flux (Indalloy flux 2, Indium Corporation, Utica, NY) and placed upright on a hot plate for 1 minute to raise the temperature of the flux to approximately $100^{\circ} \mathrm{C}$. The wire was then immersed in liquid $\mathrm{Sn}$ and aged for up to 168 hours at $300{ }^{\circ} \mathrm{C}$ in a furnace. After aging, the samples were removed from the furnace and air cooled on an $\mathrm{Al}_{2} \mathrm{O}_{3}$ block.

In order to characterize the microstructure, samples were sectioned perpendicular to the fiber direction and polished to a final finish of $0.3-\mu \mathrm{m}$ alumina suspension. Image analysis software (ImageJ, National Institutes of Health, Bethesda, MD) was used to determine the area fraction of small Ti-rich particles in the NiTi fiber. Microstructural analysis was conducted using a field emission electron microscope (Hitachi S-4700, Tokyo) at a beam voltage of $15 \mathrm{kV}$. Backscattered electron imaging was used to increase phase contrast, and EDS point analysis was used to determine phase composition. The WDS analysis was performed on an SEM with a tungsten filament (JEOL* JXA-8600 Superprobe) at

*JEOL is a trademark of Japan Electron Optics Ltd., Tokyo.

$15 \mathrm{kV}$. This was done to verify the EDS data and obtain more accurate quantitative chemical analysis. The standards used for the quantitative WDS analysis were $\mathrm{TiO}_{2}$ for $\mathrm{Ti}$, pure $\mathrm{Ni}$ for $\mathrm{Ni}$, and pure $\mathrm{Sn}$ for $\mathrm{Sn}$. A PET crystal was used for analysis of $\mathrm{Ti} K_{\alpha}$ and $\mathrm{Sn} L_{\alpha}$ peaks, while a $\mathrm{ZnF}$ crystal was used for $\mathrm{Ni} K_{\alpha}$.

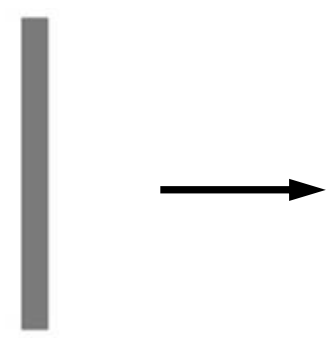

NiTi fiber etched and cleaned

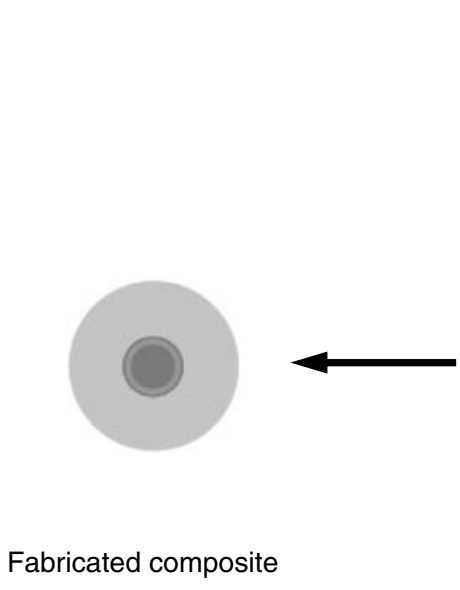

Fabricated composite

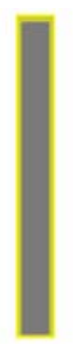

Fiber coated with flux

Composite removed From mold

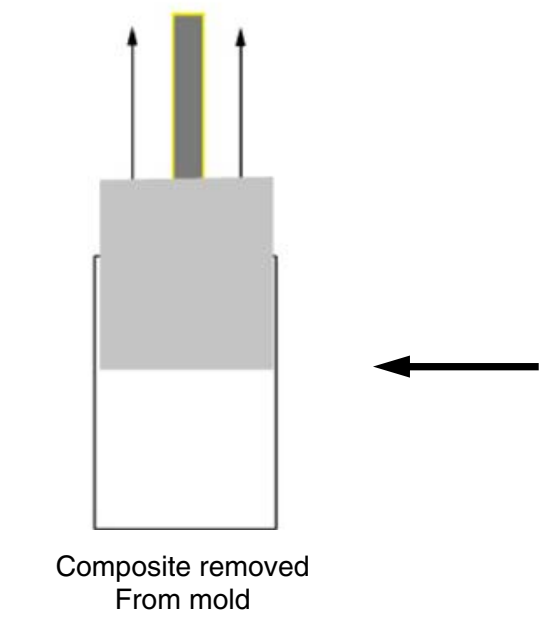

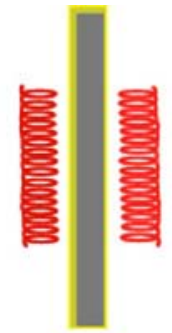

Fiber heated to bring flux to working temperature

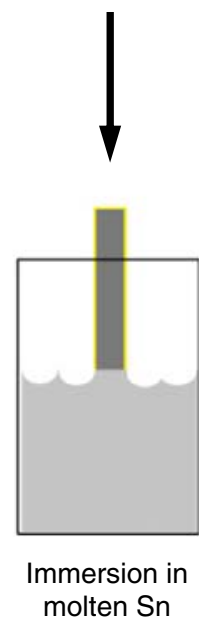

Fig. 1-NiTi-Sn composites were fabricated by immersing etched and fluxed NiTi wire into a $300{ }^{\circ} \mathrm{C}$ molten $\mathrm{Sn}$ bath for 24 to $168 \mathrm{~h}$ in a furnace. After samples were removed from the mold, they were cross sectioned and analyzed to characterize interphase growth. 
A commercial nanoindenter (MTS Nano XP-II, Minneapolis, MN) was used to measure Young's modulus and hardness of the different phases. Indentations were performed with a Berkovich indenter (threesided pyramid) to a depth of $900 \mathrm{~nm}$ at a nominal strain rate of $0.05 / \mathrm{s}$. The properties of the NiTi fiber, Sn matrix, and the reaction products between fiber and matrix were examined. Approximately 50 indentations were conducted in each component of the microstructure. In order to more accurately probe the mechanical response of small microstructural features with limited contribution from the surrounding microstructure, a dynamic contact module (DCM) was used. The DCM has an increased displacement resolution, which allows for accurate measurements to be obtained at small indentation depths (10 to $100 \mathrm{~nm})$. These experiments were also conducted with a Berkovich indenter to a final depth of $400 \mathrm{~nm}$. All indentations were performed using the continuous stiffness measurement technique. ${ }^{[25]}$ Here, a small high-frequency harmonic is superimposed over the indentation load to continuously measure the contact stiffness of the sample during loading. From this contact stiffness, the Young's modulus of the material and the hardness can be determined instantaneously as a function of depth. Calibration of the instrument was performed on a reference sample of fused silica. Modulus and hardness data from specific locations were correlated with compositions obtained via EDS and WDS to determine the effect of atomic composition on mechanical properties.

\section{RESULTS AND DISCUSSION}

\section{A. Microstructure Evolution of NiTi in Liquid Sn}

The microstructure of the as-received NiTi fiber was characterized by SEM and EDS (Figure 2). The average grain size of the fiber was approximately $5 \mu \mathrm{m}$. The EDS analysis of the fiber showed the composition to be similar to that reported by the manufacturer. Small Ti-rich particles were observed within the NiTi fiber. These had an average diameter of about $0.5 \mu \mathrm{m}$. The volume fraction of the particles in the fiber was approximately 0.4 pct. The evolution of the microstructure of the NiTi fiber-reinforced Sn matrix composites aged in liquid $\mathrm{Sn}$ at $300{ }^{\circ} \mathrm{C}$ for up to 168 hours is shown in Figure 3. Two distinct phases are present: (1) a continuous phase at the interface between the NiTi fiber and molten tin, and (2) growth of a discontinuous phase at the periphery of the first phase and in contact with liquid Sn, after approximately 72 hours (Figure 4).

The EDS and WDS analyses were used to quantify the composition across both interfacial layers. It is instructive to use the Andersen-Hasler relation ${ }^{[24]}$ to determine the interaction volume for both EDS and WDS analyses. The X-ray generating radius for a given element, $R$, is given by

$$
R=\frac{0.064\left(E_{o}^{1.68}-E_{c}^{1.68}\right)}{\rho}
$$

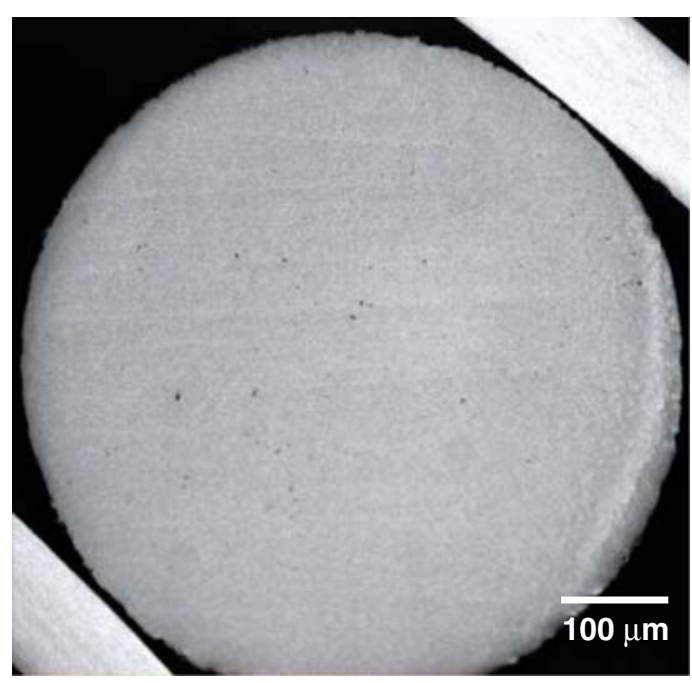

(a)

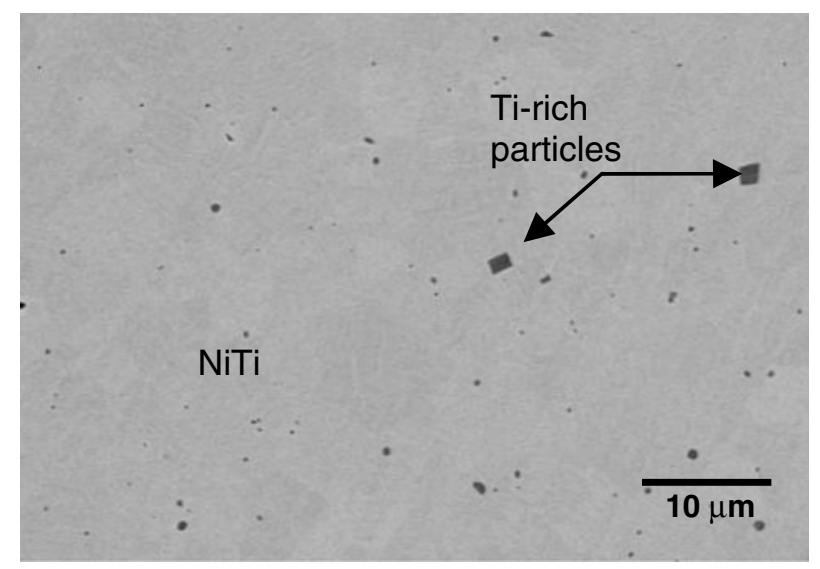

(b)

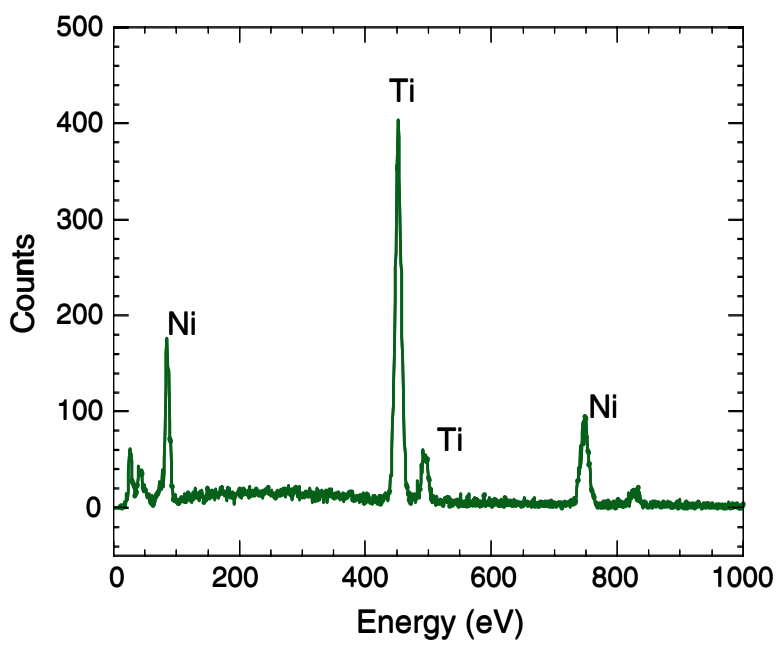

(c)

Fig. 2-(a) Microstructure analysis of NiTi wire reveals (b) binary NiTi with a grain size of approximately $5 \mu \mathrm{m}$ in diameter and Tirich particles on the order of $0.5 \mu \mathrm{m}$ in diameter and 0.3 to $0.5 \mathrm{pct}$. (c) EDS analysis of a Ti-rich particle in the NiTi matrix. Note that quantitative compositional calculations were not made due to the small particle size. 


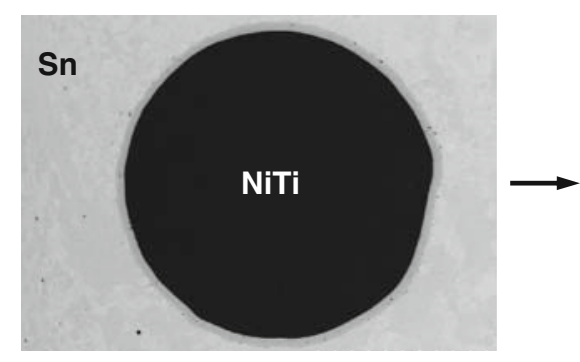

24 hours

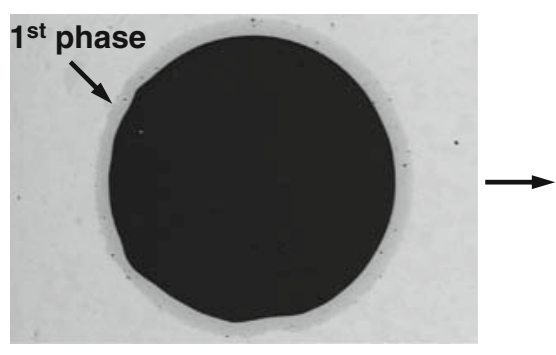

48 hours

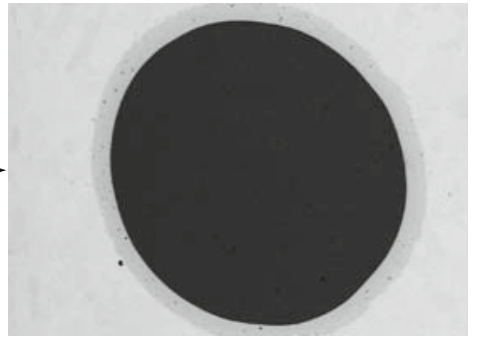

72 hours
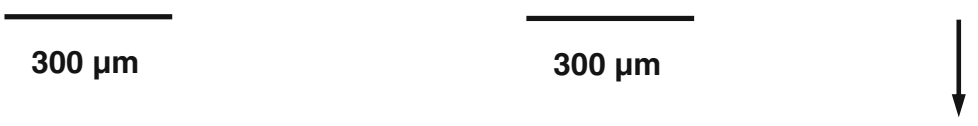

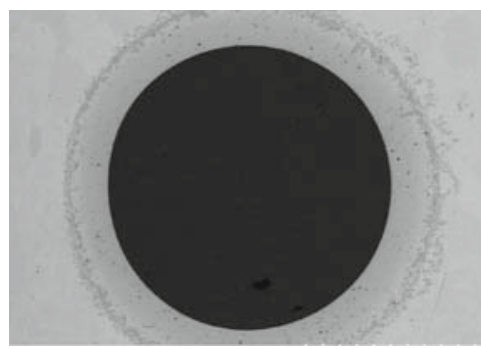

168 hours

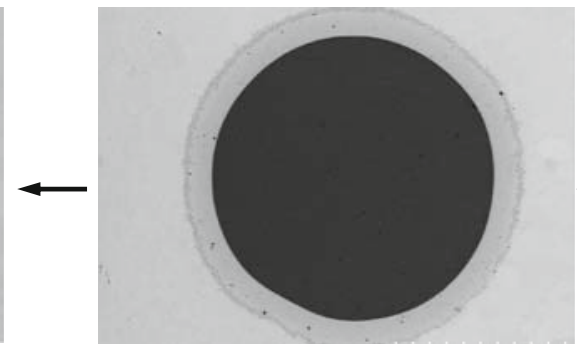

120 hours

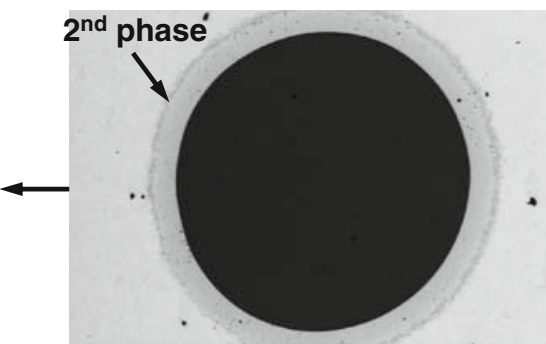

96 hours

Fig. 3-Formation of NiTi/Sn interphases over $168 \mathrm{~h}$ immersion at $300{ }^{\circ} \mathrm{C}$ shows growth of two interphases, one beginning at $72 \mathrm{~h}$ and the other beginning at $120 \mathrm{~h}$.

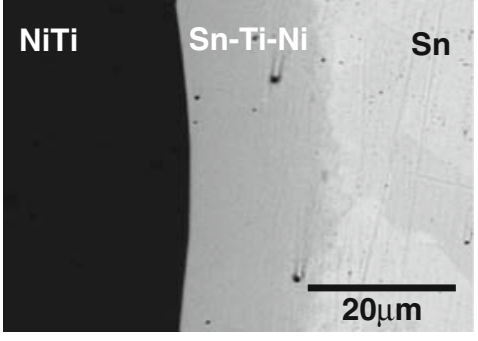

24 hours

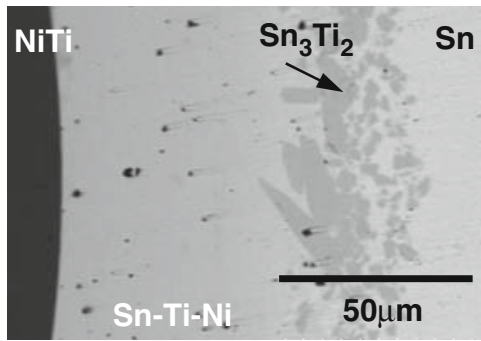

168 hours

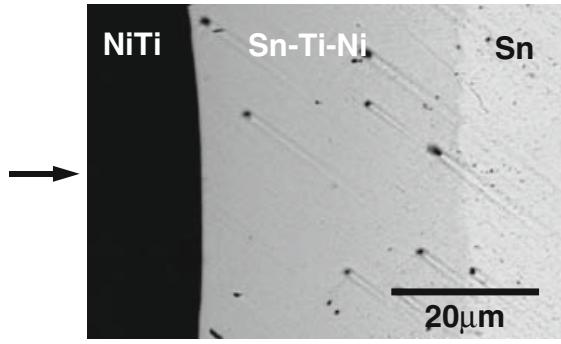

48 hours
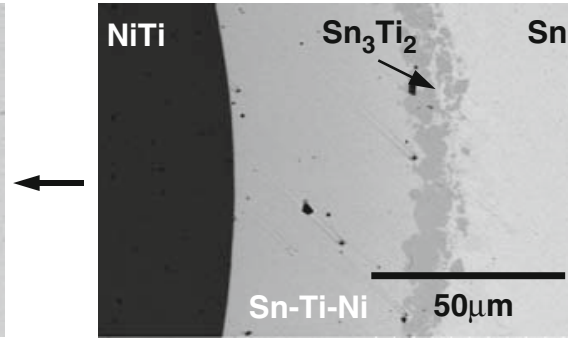

120 hours

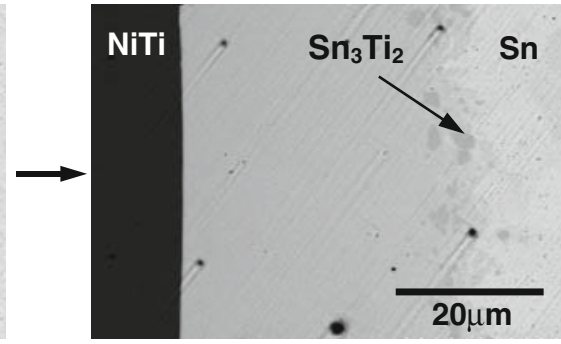

72 hours

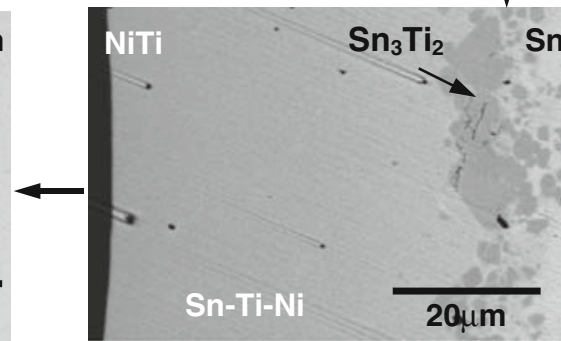

96 hours

Fig. 4-Higher magnification of interphase growth over $168 \mathrm{~h}$ immersion at $300{ }^{\circ} \mathrm{C}$ shows formation of two interphases, a Sn-Ti-Ni ternary, and $\mathrm{Sn}_{3} \mathrm{Ti}_{2}$ visible after $72 \mathrm{~h}$. Note that the micrographs at 120 and $168 \mathrm{~h}$ are at a lower magnification.

where $E_{o}$ is the electron voltage $(\mathrm{keV}), E_{c}$ is the characteristic X-ray energy $(\mathrm{keV})$ of the element of interest, and $\rho$ is the density $\left(\mathrm{g} / \mathrm{cm}^{3}\right)$ of the material. This estimation determines the electron range by combining effects of elastic scattering and energy loss due to inelastic scattering. Clearly, the radius is dependent on the density of the material being examined. Pure Sn has a density of about $7.3 \mathrm{~g} / \mathrm{cm}^{3}$, while $\mathrm{Sn}_{3} \mathrm{Ti}_{2}$ has a density 


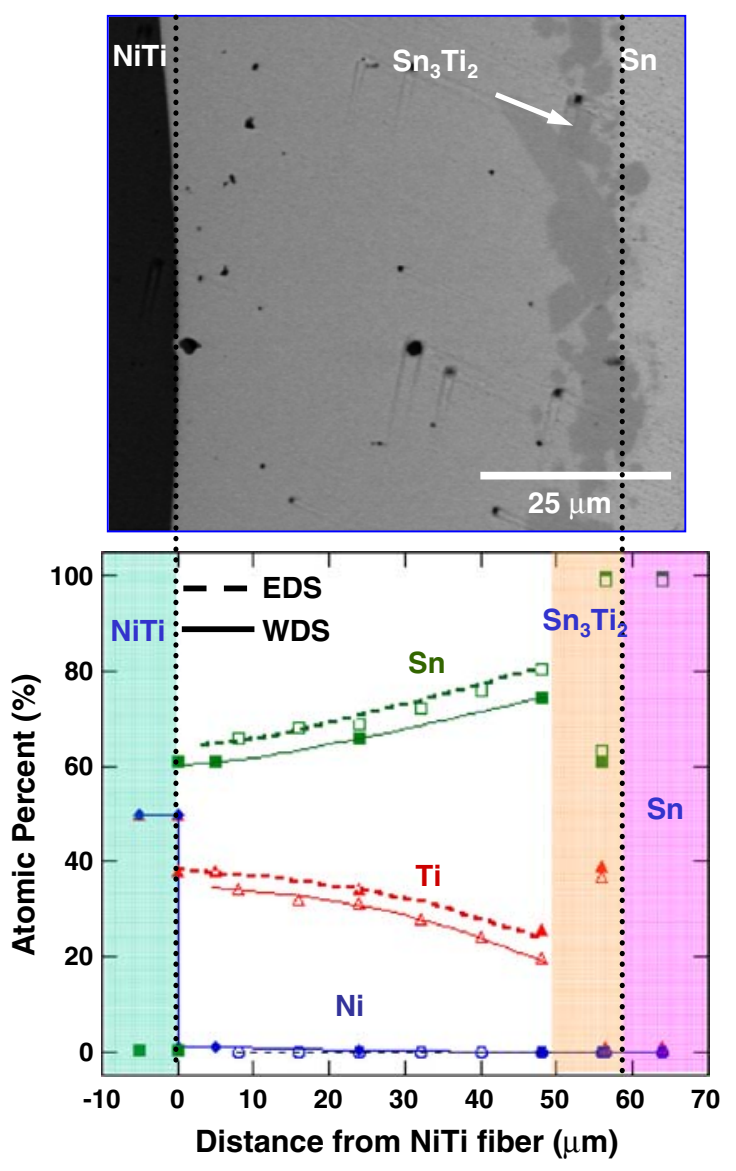

Fig. 5- Comparison of EDS and WDS data with a micrograph of the interphases. The EDS and WDS analyses reveal a variation in composition within the inner Ni-Ti-Sn phase of the composite and a $\mathrm{Sn}_{3} \mathrm{Ti}_{2}$ intermetallic for the outer phase. Additionally, WDS microprobe analysis shows Ni present in the first $20 \mu \mathrm{m}$ of the Sn-Ti-Ni phase. of $7.2 \mathrm{~g} / \mathrm{cm}^{3}$ (calculated from data given in O'Brien et al. $\left.{ }^{[28]}\right)$. Assuming a simple rule of mixtures, the density of $62 \mathrm{Sn}-38 \mathrm{Ti}$ and $82 \mathrm{Sn}-18 \mathrm{Ti}$ is between 6.2 and $6.8 \mathrm{~g} / \mathrm{cm}^{3}$, respectively. Over this range of densities, the Andersen-Hasler X-ray generation radii for $\mathrm{Sn} L_{\alpha}, \mathrm{Ti}$ $K_{\alpha}$, and Ni $K_{\alpha}$ were calculated to be 0.76 to $0.89 \mu \mathrm{m}$, 0.72 to $0.84 \mu \mathrm{m}$, and 0.57 to $0.67 \mu \mathrm{m}$, respectively. Because the solid solution layer was at least $20-\mu \mathrm{m}$ thick, and measurements on the $\mathrm{Sn}_{3} \mathrm{Ti}_{2}$ were conducted on particles about $20-\mu \mathrm{m}$ thick, the interaction volumes are much smaller than the region being analyzed.

The EDS and WDS analyses across the interfacial region show that the inner phase contains approximately 60 pct Sn, 40 pct Ti, and 1 pct Ni at the fiber surface and progressively becomes richer in $\mathrm{Sn}$ and poorer in $\mathrm{Ti}$ and $\mathrm{Ni}$ with increasing distance from the fiber (Figure 5). Thus, the inner layer appears to be a solid solution of Sn-Ti-Ni. Indeed, the backscattered SEM images show that the contrast varies continuously in the first layer, being darkest close to the NiTi wire and progressively getting lighter with increasing distance from the fiber. The outer reaction layer had a different morphology and a constant composition of approximately 63 pet $\mathrm{Sn}$ and 37 pet Ti. There was no Ni detected in the outer layer by either the EDS or WDS technique. Thus, based on these observations and the Sn-Ti phase diagram, this outer phase appears to be a stoichiometric compound of $\mathrm{Sn}_{3} \mathrm{Ti}_{2}$ (Figure 6). Kuper et al. ${ }^{[26]}$ discovered that a $\mathrm{TiSn}_{x}$ phase forms between liquid $\mathrm{Sn}$ and pure $\mathrm{Ti}$ and has a $\mathrm{Sn}$ to $\mathrm{Ti}$ ratio of approximately 1.5 . Further studies confirmed the composition of this phase to be $\mathrm{Sn}_{3} \mathrm{Ti}_{2} \cdot{ }^{[27,28]}$ Note that at the aging temperature, on the Sn-rich part of the phase diagram, there is a two-phase region where $\mathrm{Sn}_{3} \mathrm{Ti}_{2}$ and liquid $\mathrm{Sn}$ coexist, in agreement with our observations.
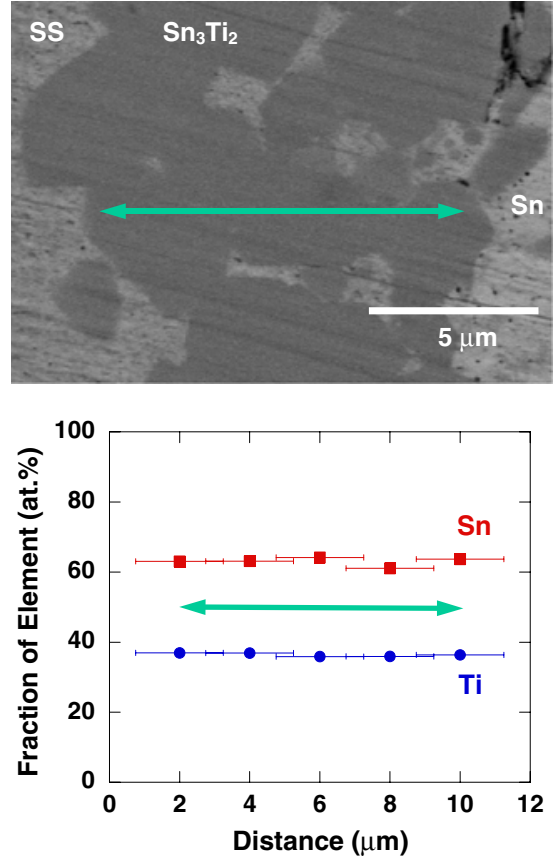

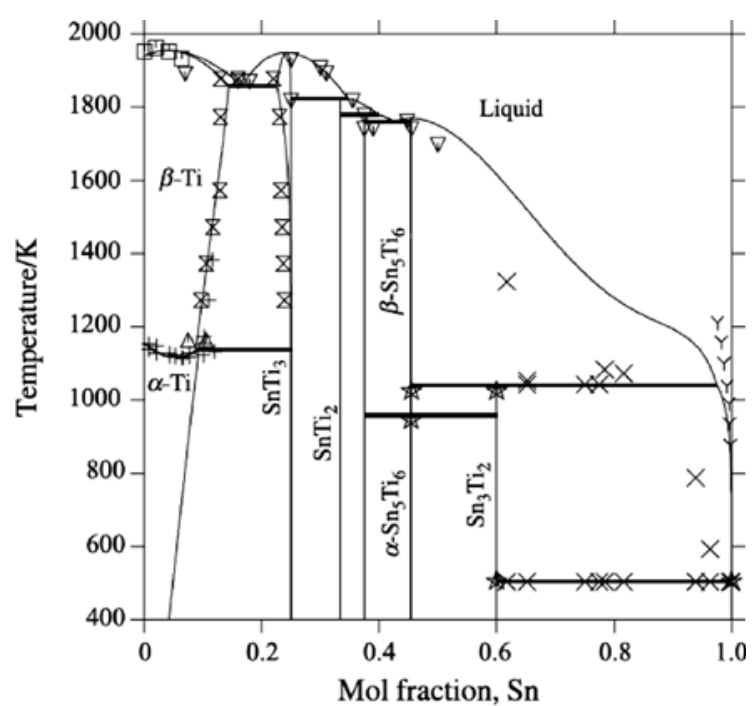

Mol fraction, Sn

Fig. 6- $\mathrm{Sn}$-Ti binary phase diagram showing $\mathrm{Sn}_{3} \mathrm{Ti}_{2}$ intermetallic formation at 0.6 mol pet $\mathrm{Sn} .{ }^{[28]}$ 


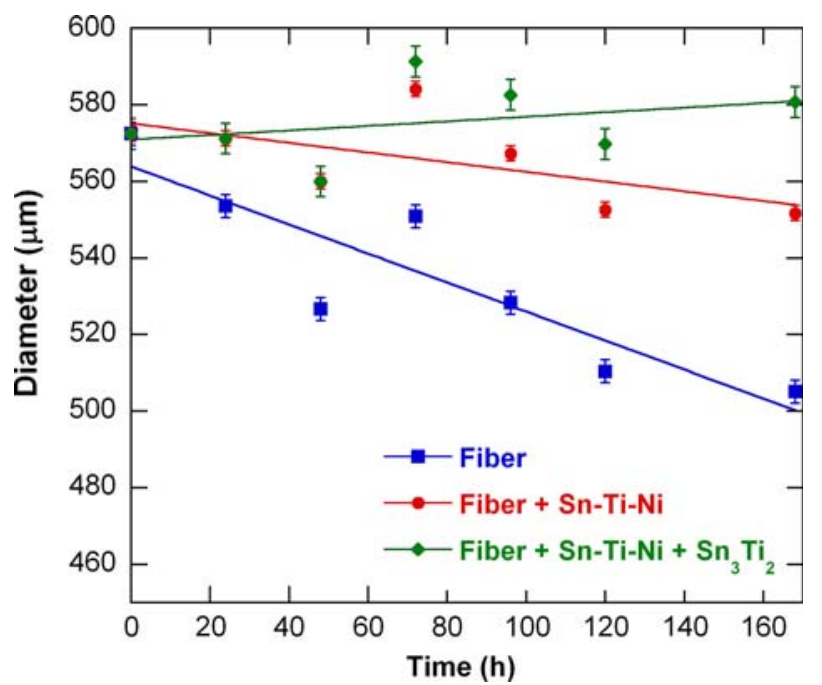

Fig. 7-Thickness of various aspects of Ni-Ti-Sn microstructure over time at $300{ }^{\circ} \mathrm{C}$ show initial net diffusion into the wire, followed by formation of $\mathrm{Sn}_{3} \mathrm{Ti}_{2}$ intermetallic growing out into the liquid $\mathrm{Sn}$.

The evolution of the diameter of the NiTi fiber and thickness of each interphase gives additional insight into the possible diffusion mechanisms taking place (Figure 7). The NiTi fiber diameter decreases with increasing aging time, while the thickness of the inner and outer layers increases. A schematic illustrating the proposed diffusion mechanisms during aging is shown in Figure 8. Initially, $\mathrm{Sn}, \mathrm{Ti}$, and $\mathrm{Ni}$ interdiffuse to form $\mathrm{Sn}-\mathrm{Ti}-\mathrm{Ni}$ solid solution. The growth front moves into the fiber, so Sn diffuses faster into the fiber than Ti can diffuse into liquid Sn. It is interesting to note that the presence of $\mathrm{Ni}$ within the intermediate layer causes it to remain as a solid solution of Sn-Ti-Ni. At the periphery of this layer, as soon as the $\mathrm{Ni}$ concentration goes to zero, $\mathrm{Sn}_{3} \mathrm{Ti}_{2}$ is formed from the reaction between $\mathrm{Sn}$ and $\mathrm{Ti}$ (as described by the binary $\mathrm{Sn}-\mathrm{Ti}$ phase diagram).

\section{B. Mechanical Properties of Interfacial Products by Nanoindentation}

Nanoindentation was used to correlate the mechanical properties of the interfacial layers with the measured composition through the microstructure. Indentations in NiTi, Sn, Sn-Ti-Ni solid solution, and $\mathrm{Sn}_{3} \mathrm{Ti}_{2}$ intermetallic were conducted. A strong relationship between composition and measured hardness/ modulus was observed. Figure 9 shows indentations in the Sn-Ti-Ni solid solution layer. The Young's modulus and hardness $v s$ indentation depth are also shown. The modulus and hardness are essentially constant over the indentation depth. Note that with increasing distance from the NiTi fiber, i.e., an increase in the amount of Sn (decrease in Ti), the Young's modulus and hardness decrease.

Indentations in the $\mathrm{Sn}_{3} \mathrm{Ti}_{2}$ intermetallic are shown in Figure 10. Note that the indentation is well within the intermetallic particle (the small microcracks are due to polishing and were not observed in all intermetallic

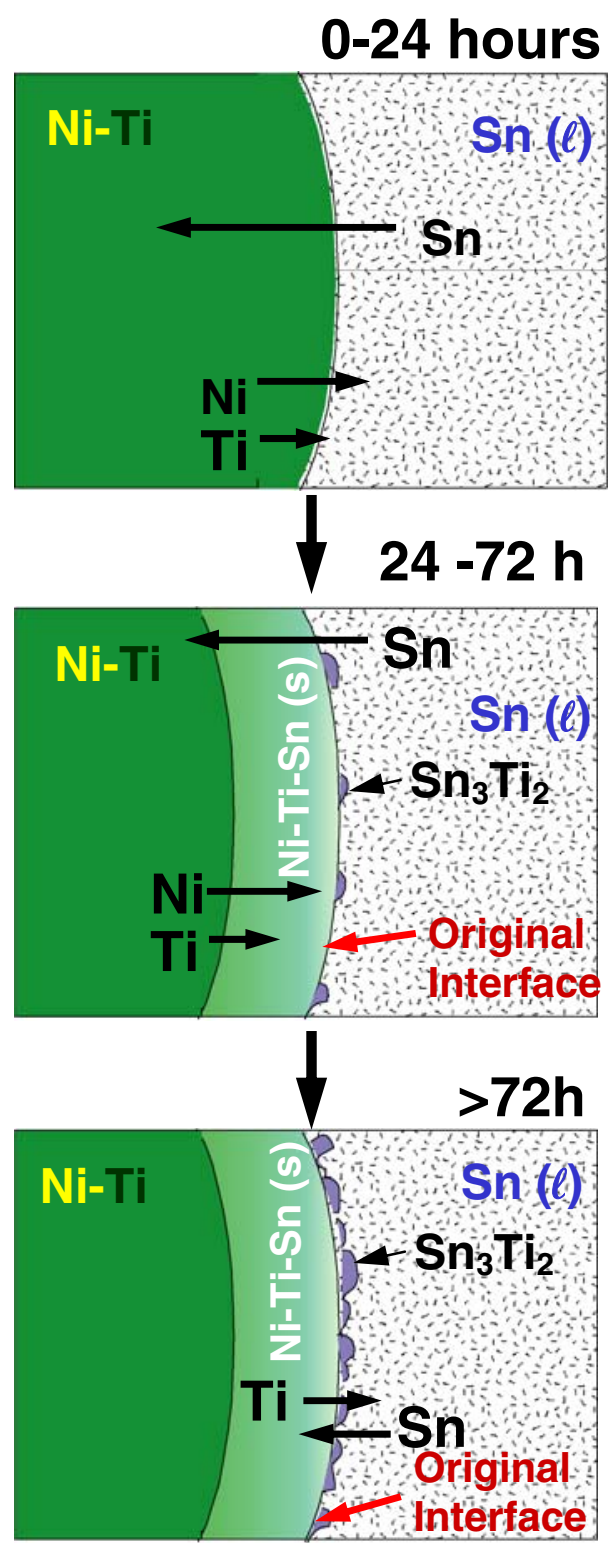

Fig. 8- Schematic illustrating the diffusion characteristics of the $\mathrm{Ni}-\mathrm{Ti}-\mathrm{Sn}$ system at $300{ }^{\circ} \mathrm{C}$. Initial interdiffusion of $\mathrm{Sn}, \mathrm{Ni}$, and $\mathrm{Ti}$ creates a ternary Ni-Ti-Sn phase with 1.0 at. pet solubility of $\mathrm{Ni}$. After $72 \mathrm{~h}$, the amount of $\mathrm{Ni}$ at the growth front is low enough to enable outward growth of the binary $\mathrm{Sn}_{3} \mathrm{Ti}_{2}$ intermetallic.

particles). Particular care was taken to extract modulus and hardness information at shallower depths (50 to $100 \mathrm{~nm}$ ) where a "plateau" was present. The reason is that at larger depths the intermetallic islands were somewhat prone to "sink" in the Sn matrix. This was captured by sharp decreases in modulus and hardness at larger indentation depths $(>200 \mathrm{~nm})$. Figure 10 shows the location of indentations in the $\mathrm{Sn}_{3} \mathrm{Ti}_{2}$ intermetallic. Figure 11 shows the modulus and hardness as a function of position, beginning at the NiTi fiber and ending in the pure $\mathrm{Sn}$ region. Note that the evolution of composition in $\mathrm{Sn}-\mathrm{Ti}-\mathrm{Ni}$ is directly related to the modulus and hardness. It is interesting to note that the $\mathrm{Sn}_{3} \mathrm{Ti}_{2}$ intermetallic has a higher modulus and hardness than 


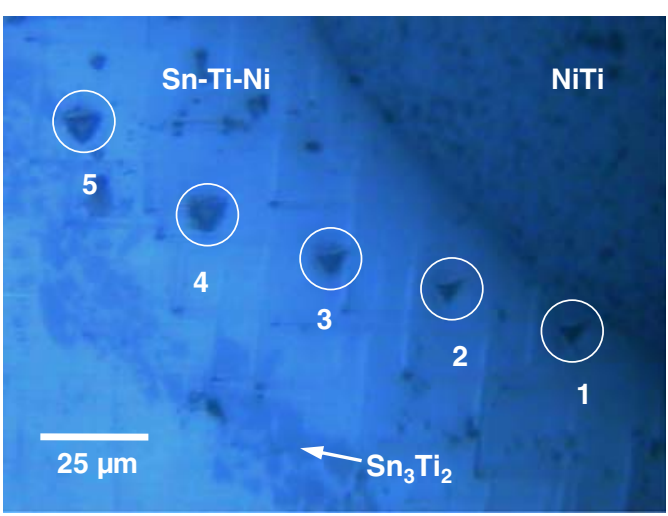

(a)

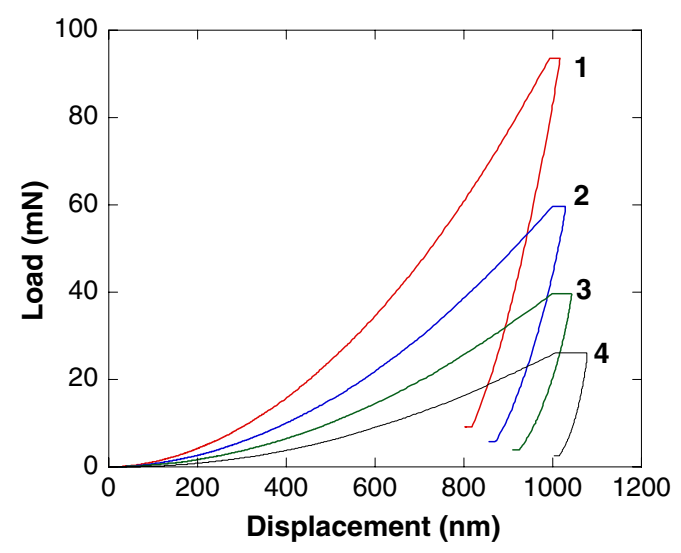

(b)

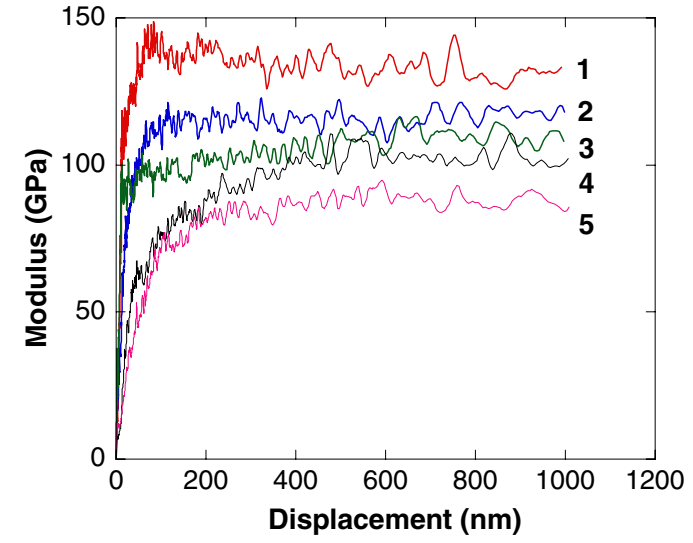

(c)

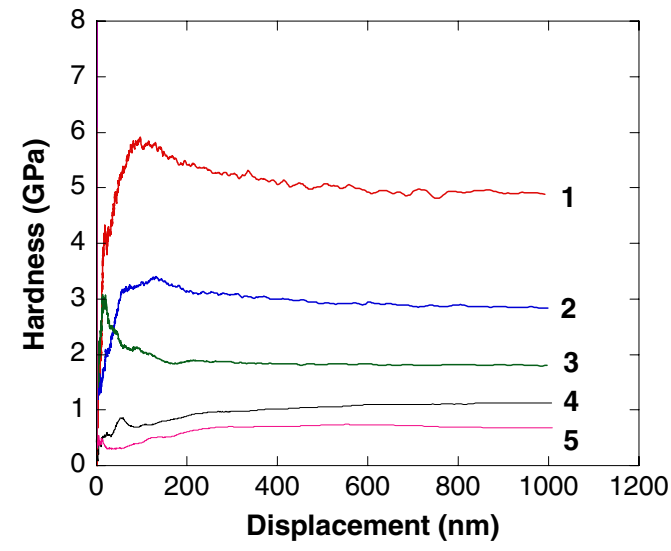

(d)

Fig. 9-(a) Indentations in Sn-Ti-Ni solid solution, $(b)$ load displacement, $(c)$ modulus $v s$ displacement, and $(d)$ hardness $v s$ displacement curves for the locations shown in part (a). Note that, as Sn content increases, the modulus and hardness decrease.
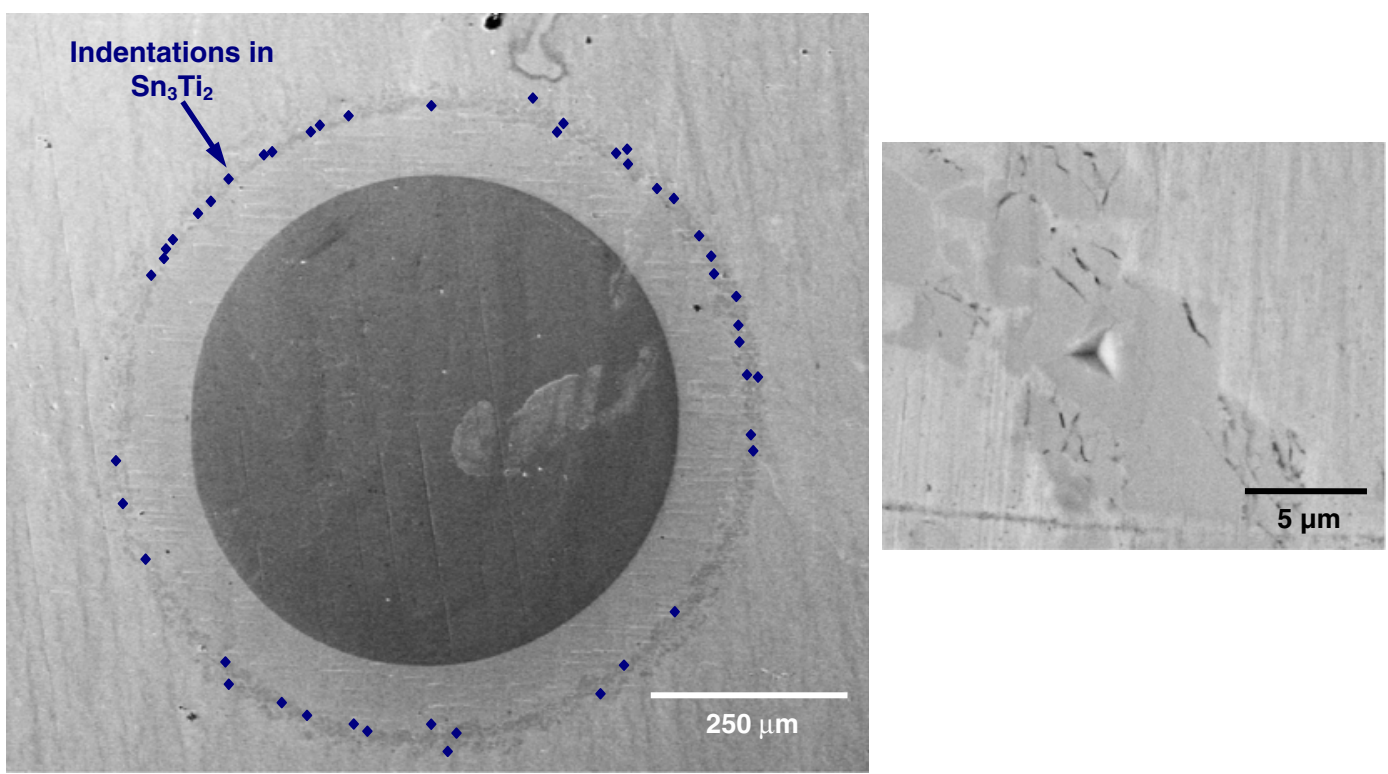

Fig. 10-Locations of nanoindentations performed on $\mathrm{Sn}_{3} \mathrm{Ti}_{2}$ intermetallic. Indentations were performed only on the largest nodules and at very shallow depths to reduce the effects from the surrounding matrix. 
Table I. Young's Modulus and Hardness Measured by Nanoindentation

\begin{tabular}{lcccc}
\hline Material & $\begin{array}{c}\text { Young's Modulus } \\
(\mathrm{GPa})\end{array}$ & $\begin{array}{c}\text { Literature Value of } \\
\text { Modulus }(\mathrm{GPa})\end{array}$ & $\begin{array}{c}\text { Hardness } \\
(\mathrm{GPa})\end{array}$ & $\begin{array}{c}\text { Literature Value of } \\
\text { Hardness }(\mathrm{GPa})\end{array}$ \\
\hline $\mathrm{NiTi}$ & $68.3 \pm 1.8$ & $69 \pm 5^{[29]}$ & $3.4 \pm 0.2$ & - \\
$\mathrm{Sn}$ & $45.5 \pm 1.4$ & $46.7 \pm 2.7^{[30]}$ & $0.16 \pm 0.03$ & $0.22 \pm 0.03^{[30]}$ \\
$\mathrm{Sn}_{3} \mathrm{Ti}_{2}$ & $144.3 \pm 13.2$ & - & $8.7 \pm 0.9$ & - \\
\hline
\end{tabular}

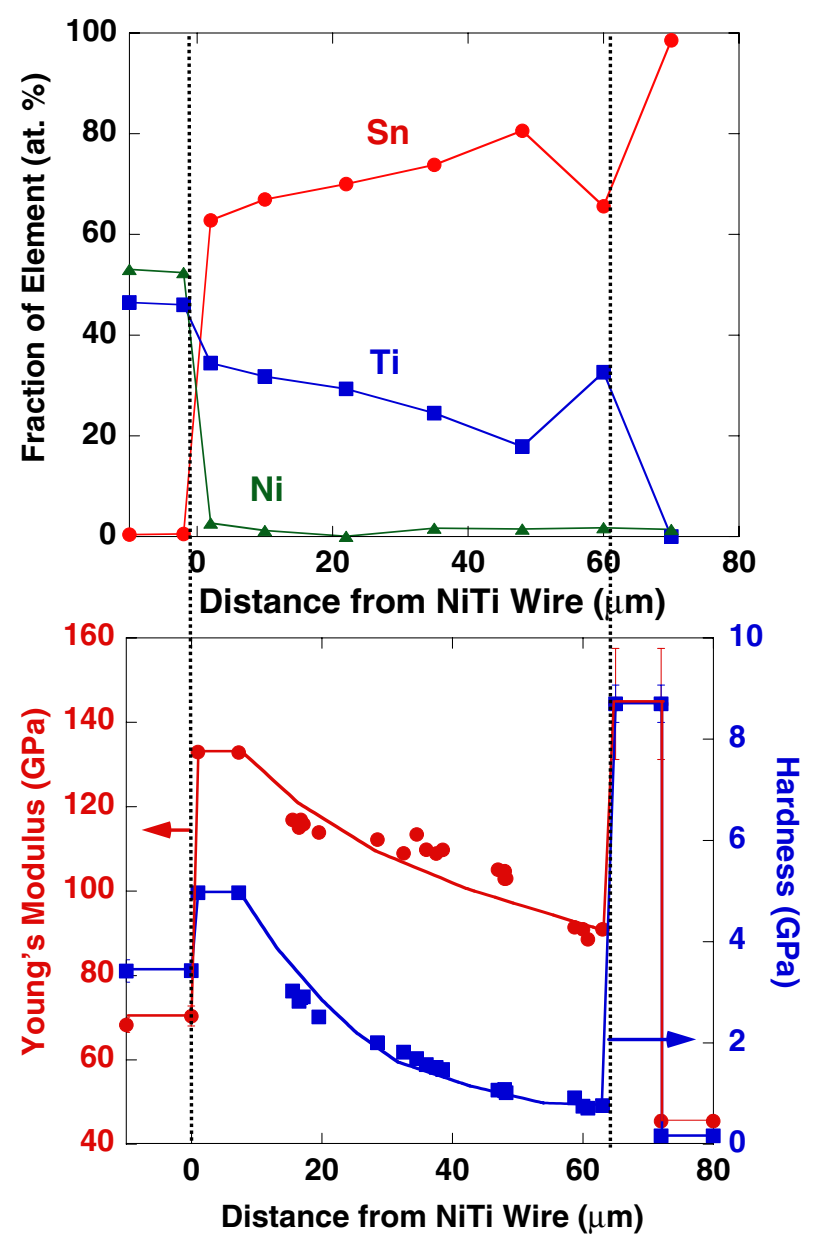

Fig. 11-Correlation between the atomic composition and hardness/ modulus of interphases in the Ni-Ti-Sn system.

the Sn-Ti-Ni phase over the entire range of its composition. Furthermore, it is clear that this compound is an intermetallic compound, because both the modulus and hardness are higher than those of the region of the nominally same composition in the solid solution layer. Thus, it is quite clear that the first phase appears to be a $\mathrm{Sn}-\mathrm{Ni}$-Ti solid solution and the second is the $\mathrm{Sn}_{3} \mathrm{Ti}_{2}$ intermetallic described by Kuper et al. ${ }^{[26]}$ Table I shows a comparison of the modulus and hardness measured for $\mathrm{Sn}_{3} \mathrm{Ti}_{2}$ in our study. A comparison of measurements on NiTi and $\mathrm{Sn}$, with that reported in the literature, shows very good agreement, indicating that the nanoindentation technique used here is quite accurate in probing mechanical properties at small volumes.

\section{CONCLUSIONS}

We have studied the interfacial reactions between NiTi fibers in a liquid Sn matrix. The relationship between the composition of the interfacial phases and their mechanical properties was investigated. Based on the results of this work, the following conclusions can be made.

1. Immersion of NiTi fiber in liquid $\mathrm{Sn}$ at $300{ }^{\circ} \mathrm{C}$ for up to 168 hours resulted in two interfacial reaction layers. The EDS and WDS analyses show that the first layer to form is a ternary solid solution of $\mathrm{Sn}$ Ti-Ni. At the periphery of this layer, where the concentration of $\mathrm{Ni}$ is close to zero, $\mathrm{Sn}$ reacts with $\mathrm{Ti}$ to form $\mathrm{Sn}_{3} \mathrm{Ti}_{2}$.

2. Nanoindentation revealed that the hardness and modulus of the $\mathrm{Sn}-\mathrm{Ti}-\mathrm{Ni}$ phase are directly related to composition. The $\mathrm{Sn}_{3} \mathrm{Ti}_{2}$ phase had a higher modulus and hardness than the Sn-Ti-Ni phase at a similar composition, suggesting that it is indeed a stoichiometric intermetallic compound.

\section{ACKNOWLEDGMENTS}

One of the authors (JPC) acknowledges Intel Corporation for an ASU-Intel graduate fellowship. The authors acknowledge the financial support for this research from Intel (Drs. D. Suh, R. Mahajan, and V. Wakharkar). The authors also thank (1) Gordon Moore from the Department of Chemistry and Biochemistry at Arizona State University for his help with the WDS and (2) Memry Corporation for providing the NiTi fibers used in this study.

\section{REFERENCES}

1. S. Kang and A.K. Sarkhel: J. Electron. Mater., 1994, vol. 23, p. 701 .

2. D.R. Frear and P.T. Vianco: Metall. Mater. Trans. A, 1994, vol. $25 \mathrm{~A}$, p. 1509 .

3. J. Glazer: Int. Mater. Rev., 1995, vol. 40, p. 65.

4. M. Abtew and G. Selvaduray: Mater. Sci. Eng. R, 2000, vol. 27, p. 95.

5. W.J. Plumridge: Monatshefte Chem., 2005, vol. 136, p. 1811.

6. P.T. Vianco and D.R. Frear: J. Electron. Mater., 1993, vol. 45, p. 14.

7. S. Choi, K.N. Subramanian, J.P. Lucas, and T.R. Bieler: J. Electron. Mater., 2000, vol. 29, p. 1249.

8. S. Terashima, K. Yoshiharu, H. Takuya, and T. Masamoto: J. Electron. Mater., 2003, vol. 32, p. 1527. 
9. M.A. Meyers and K.K. Chawla: Mechanical Behavior of Materials, Prentice Hall, Upper Saddle River, NJ, 1999.

10. K. Otsuka and C.M. Wayman: Shape Memory Materials, Cambridge University Press, Cambridge, United Kingdom, 1998.

11. C.P. Frick, A.M. Ortega, J. Tyber, A. Maksound, H.J. Maier, Y. Liu, and K. Gall: Mater. Sci. Eng. A, 2005, vol. 405, p. 34.

12. A. Shimamoto, H.Y. Zhao, and H. Abe: Int. J. Fatigue, 2004, vol. 26, p. 533.

13. D. Vokoun, V. Kafka, and C.T. Hu: Smart Mater. Struct., 2003, vol. 12 , p. 680.

14. M. Wagner, T. Sawaguchi, G. Kausträter, D. Höffken, and G. Eggeler: Mater. Sci. Eng. A, 2004, vol. 378, p. 105.

15. Z.G. Wang, X.T. Zua, Y.Q. Fub, and L.M. Wang: Thermochimica Acta, 2005, vol. 428, p. 199.

16. J.M. Young and K.J. Van Vliet: J. Biomed. Mater. Res., 2005, vol. 72 , p. 17.

17. Y. Zheng, L. Cui, and J. Schrooten: Appl. Phys. Lett., 2004 , vol. 84 , p. 31 .

18. L.C. Brinson, I. Schmidt, and R. Lammering: J. Mech. Phys. Solids, 2004, vol. 52, p. 1549.

19. Z.G. Wei, R. Sandstrom, and S. Miyazaki: J. Mater. Sci., 1998, vol. 33 , p. 3763.
20. I. Dutta, B.S. Majumdar, D. Pan, W.S. Horton, W. Wright, and Z.X. Wang: J. Electron. Mater., 2004, vol. 33, p. 258.

21. Z.X. Wang, I. Dutta, and B.S. Majumdar: Mater. Sci. Eng. A, 2006, vol. 421, p. 133.

22. Z.X. Wang, I. Dutta, and B.S. Majumdar: Scripta Mater., 2006, vol. 54 , p. 627.

23. O. Fouassier, J. Chazelas, and J. Silvain: Compos. Part A, 2002, vol. 33, p. 1391.

24. C.A. Anderson and M.F. Hasler: Proc. 4th Int. Conf. on X-ray Optics and Microanalysis, R. Castaing, P. Deschamps, and J. Philibert, eds., Hermann, Paris, 1966, pp. 310-27.

25. W.C. Oliver and G.M. Pharr: J. Mater. Res., 2004, vol. 19, p. 3.

26. C. Kuper, W. Peng, A. Pisch, F. Goesmann, and R. Scmid-Fetzer: Z. Metallkd., 1998, vol. 89, p. 855.

27. C. Liu, U.E. Klotz, P.J. Uggowitzer, and J.F. Loeffler: Monatshefte Chem., 2005, vol. 136, p. 1921.

28. J.W. O'Brien, R.A. Dunlap, and J.R. Dahn: J. Alloys Compd., 2003, vol. 353, p. 60.

29. D.C. Dunand, D. Mari, M.A.M. Bourke, and J.A. Roberts: Metall. Mater. Trans. A, 1996, vol. 27A, pp. 2820-36.

30. X. Deng, N. Chawla, K.K. Chawla, and M. Koopman: Acta Mater., 2004, vol. 52, pp. 4291-4303. 